\title{
BMJ Open Identifying socioeconomic, epidemiological and operational scenarios for tuberculosis control in Brazil: an ecological study
}

\author{
Daniele Maria Pelissari, ${ }^{1}$ Marli Souza Rocha, ${ }^{1}$ Patricia Bartholomay, ${ }^{1}$ \\ Mauro Niskier Sanchez, ${ }^{2,3}$ Elisabeth Carmen Duarte, ${ }^{4}$ Denise Arakaki-Sanchez, ${ }^{1}$ \\ Cíntia Oliveira Dantas, ${ }^{1}$ Marina Gasino Jacobs, ${ }^{1}$ Kleydson Bonfim Andrade, ${ }^{1}$ \\ Stefano Barbosa Codenotti, ${ }^{1}$ Elaine Silva Nascimento Andrade, ${ }^{1}$ \\ Wildo Navegantes de Araújo, ${ }^{3,5}$ Fernanda Dockhorn Costa, ${ }^{1}$ \\ Walter Massa Ramalho, ${ }^{5}$ Fredi Alexander Diaz-Quijano ${ }^{6}$
}

To cite: Pelissari DM, Rocha MS, Bartholomay $\mathrm{P}$, et al. Identifying socioeconomic, epidemiological and operational scenarios for tuberculosis control in Brazil: an ecological study. BMJ Open 2018;8:e018545. doi:10.1136/ bmjopen-2017-018545

- Prepublication history and additional material for this paper are available online. To view these files, please visit the journal online (http://dx.doi org/10.1136/bmjopen-2017018545).

Received 6 July 2017

Revised 7 March 2018 Accepted 2 May 2018

Check for updates

${ }^{1}$ National Tuberculosis Program of Brazil, Ministry of Health, Brasília, Distrito Federal, Brazil ${ }^{2}$ Department of Public Health, University of Brasília, Brasília, Distrito Federal, Brazil

${ }^{3}$ Institute of Health Technology Assessment, Porto Alegre, Rio Grande do Sul, Brazil

${ }^{4}$ Medical School, University of Brasília, Brasília, Distrito Federal, Brazil

${ }^{5}$ Faculty of Ceilandia, University of Brasília, Brasília, Distrito Federal, Brazil

${ }^{6}$ Department of Epidemiology, School of Public Health, University of São Paulo, São Paulo, São Paulo, Brazil

Correspondence to Daniele Maria Pelissari; daniele.pelissari@saude.gov.br

\section{ABSTRACT}

Objectives To identify scenarios based on socioeconomic, epidemiological and operational healthcare factors associated with tuberculosis incidence in Brazil.

Design Ecological study.

Settings The study was based on new patients with tuberculosis and epidemiological/operational variables of the disease from the Brazilian National Information System for Notifiable Diseases and the Mortality Information System. We also analysed socioeconomic and demographic variables.

Participants The units of analysis were the Brazilian municipalities, which in 2015 numbered 5570 but 5 were excluded due to the absence of socioeconomic information.

Primary outcome Tuberculosis incidence rate in 2015.

Data analysis We evaluated as independent variables the socioeconomic (2010), epidemiological and operational healthcare indicators of tuberculosis (2014 or 2015) using negative binomial regression. Municipalities were clustered by the k-means method considering the variables identified in multiple regression models. Results We identified two clusters according to socioeconomic variables associated with the tuberculosis incidence rate (unemployment rate and household crowding): a higher socioeconomic scenario $(n=3482$ municipalities) with a mean tuberculosis incidence rate of $16.3 / 100000$ population and a lower socioeconomic scenario (2083 municipalities) with a mean tuberculosis incidence rate of 22.1/100000 population. In a second stage of clusterisation, we defined four subgroups in each of the socioeconomic scenarios using epidemiological and operational variables such as tuberculosis mortality rate, AIDS case detection rate and proportion of vulnerable population among patients with tuberculosis. Some of the subscenarios identified were characterised by fragility in their information systems, while others were characterised by the concentration of tuberculosis cases in key populations.

Conclusion Clustering municipalities in scenarios allowed us to classify them according to the socioeconomic,

\section{Strengths and limitations of this study}

- This study was based on national population data in a country of continental dimension (5565 municipalities).

- The availability of variables associated with tuberculosis made it possible to consider both socioeconomic and epidemiological/operational approaches in the definition of municipality clusters for tuberculosis control.

- This methodology can be explored by other countries to guide their plans to end tuberculosis.

- Reporting and information quality may vary between sources and periods which could affect estimate accuracy.

- Inferences obtained are applicable to population groups, not to individuals. However, ecological research can provide evidence to support public health decisions.

epidemiological and operational variables associated with tuberculosis risk. This classification can support targeted evidence-based decisions such as monitoring data quality for improving the information system or establishing integrative social protective policies for key populations.

\section{INTRODUCTION}

In 2016, 10.4 million people had tuberculosis (TB) and 1.8 million died worldwide because of the disease. ${ }^{1}$ In Brazil, similar to other countries, TB incidence reduction $(37.9 / 100000$ population in 2007 to $32.4 / 100000$ population in 2016) ${ }^{2}$ seems to be associated with the improvement of population living conditions $^{3-5}$ and the performance of TB control programmes. ${ }^{6}$ However, the disease burden continues to be significant in the country, with 66796 new patients registered in $2016 .^{2}$ 
In 2014, in a move towards elimination, the WHOlaunched the End TB Strategy, setting targets to be met by 2035 , including a $90 \%$ reduction in TB incidence compared with $2015 .{ }^{1}$ The strategy is critical to energising the fight against the disease and mobilising resources, but needs to be adapted to the local context, as does any other health policy. ${ }^{7}$

Some countries have already made progress developing their national plans. Among the strategies presented, we highlight the strengthening of existing TB services, the acceleration of case detection in key populations and the implementation of actions to reduce barriers to $\mathrm{TB}$ care. ${ }^{8-10}$

Brazil is a country with continental dimensions; thus, both socioeconomic indicators ${ }^{11}$ and those that reflect the performance of local TB programmes ${ }^{2}$ present a high degree of heterogeneity. Considering this context, and to support the 'National Plan to End TB', ${ }^{12}$ we identified scenarios based on socioeconomic, epidemiological and operational factors associated with the TB incidence rate.

\section{METHODS}

\section{Type of study and data source}

This is an ecological study, with the units of analysis being the Brazilian municipalities which were 5570 in 2015 . We excluded five municipalities due to absence of socioeconomic information. Data on socioeconomic and demographic variables by municipality were only available from the last population census (2010). ${ }^{11} 13$ For new patients with TB (2015) and epidemiological/operational variables of the disease (2014 and 2015), we used data from the Brazilian National Information System for Notifiable Diseases and the Mortality Information System. ${ }^{11}$

\section{Variables}

The dependent variable was the TB incidence rate (new cases that arose in a year per 100000 population) in 2015, and the independent variables were socioeconomic, epidemiological and healthcare operational TB variables. Many of these variables have already been identified in previous studies as TB determinants (online supplementary material 1). ${ }^{314-16}$

The socioeconomic variables analysed were as follows:

- Municipal Human Development Index (M-HDI).

- Average household income per capita.

- Gross domestic product (GDP) per capita.

- Proportion of the population that is extremely poor, poor and vulnerable to poverty.

- Gini coefficient.

- Unemployment rate.

- Illiteracy rate.

- Proportion of population living in households with more than two people per room representing household crowding.

- Infant mortality rate per 1000 live births.

- Life expectancy at birth.
- Population size of municipalities classified as small (less than 20000 inhabitants), medium (20000-99999 inhabitants) and large (100000 inhabitants or larger). ${ }^{17}$

Average household income per capita and GDP per capita were converted into US\$ using the average annual price in 2010 (US $\$ 1 \approx \mathrm{R} \$ 1.8$ [Brazilian Reals-R $\$$ ]). We adopted the Brazilian definitions for the proportions of the population that are extremely poor, poor and vulnerable to poverty: proportion of individuals in the municipality with an average household income per capita equal or less than US $\$ 40$, US $\$ 80$ and US $\$ 145$, respectively. ${ }^{13}$

The epidemiological variables of TB were as follows:

- AIDS case detection rate per 100000 population.

- Proportion of new patients with TB who were: HIV positive, prisoners, health professionals, indigenous, homeless and, as a composite indicator, the proportion of patients with TB from at least one of these vulnerable groups. Those vulnerabilities were previously associated with an increased risk of TB in other studies. $^{3-5} 18$

- Proportion of TB retreatment patients.

- TB mortality rate per 100000 population.

The operational healthcare variables of TB considered in the analysis were as follows:

- Proportions of new patients with TB: in which contacts were examined, laboratory confirmed, tested for HIV and the treatment outcomes (cure, loss to follow-up and no record of TB outcome).

- Proportion of sputum culture examination among retreatment patients.

Due to the availability of updated data at the time of analysis, the data to calculate culture examinations, treatment outcomes and TB mortality rate refers to 2014, while the other epidemiological and operational variables refers to 2015 .

\section{Statistical analysis}

Statistical analysis was performed in two stages; each of them included a model to identify the factors associated with TB incidence rate. This evaluation was followed by a cluster analysis based on the factors identified. The first stage was focused on socioeconomic variables and the second on the epidemiological and operational variables associated with TB incidence rate.

Negative binomial regression was used to identify factors associated with the TB incidence rate in 2015. For these regression analyses, we only included municipalities that presented a mean annual variation of the triennial moving average of the incidence rate for the years 20012015 between $-8 \%$ and $8 \%$. By doing so, we intended to reduce possible biases due to the variability of values in small municipalities and any possible intermittence in case reporting.

To obtain multiple regression models that were parsimonious and robust, we avoided including variables that were strongly correlated with each other or those that showed signs of multicollinearity (ie, inversion of the 
correlation coefficient together with an increase in SE). Whenever a strong correlation between independent variables (Spearman's $r>0.6$ ) was identified, for the multiple model, we selected the variable with the highest association with TB incidence rate in univariate regression models. We used a stepwise forward selection method and preserved the variables with a $\mathrm{p}<0.05$ in the multiple model. In addition, we adjusted the models by categories of the population size of municipalities (small: less than 20000 inhabitants, medium: 20000-99999 inhabitants and large: 100000 inhabitants or larger). We presented the association measures as the relative increment in the incidence rate (RIIR), which was obtained by subtracting one from the incidence rate ratio ((IRR-1)x100\%).

Socioeconomic variables associated in a multiple model (primary model) were considered for a cluster analysis of all municipalities using the non-hierarchical k-means method. In this method, the algorithm aims to reduce intragroup variance and maximise intergroup variance in relation to the Euclidean distance established by the variables selected. ${ }^{19}$ To define the number of clusters, we used the Elbow method, which relates the number of clusters with the percentage of internal variation of the groups, ${ }^{19}$ adopting $>60 \%$ as the cut-off point and among these, the smallest number of possible clusters.

In a second stage, epidemiological/operational variables were modelled for each socioeconomic scenario, following a similar methodology described for socioeconomic variables. Factors associated with $\mathrm{TB}$ in these secondary models, as well as the TB mortality rate, were considered for a second cluster analysis, which subdivided the previous socioeconomic clusters into epidemiological/operational TB subscenarios. Because some operational variables were only measurable during the care of patients with $\mathrm{TB}$, these second-stage methods were applied only in municipalities with patients with TB reported in 2014 and 2015.

Statistical analyses were performed with the Stata statistical package V.12.0, R V.3.3.1 and the cluster library.

\section{Patient and public involvement}

Patient and public were not involved in this study because all variables studied correspond to data aggregated by municipalities. Therefore, researchers did not have access to any individual data or personal identification of patients with TB. The results will be disseminated for Tuberculosis Control Programmes in municipalities and states and the grouping of municipalities presented in this study has already been incorporated into the Brazilian National Plan to End TB. ${ }^{12}$

\section{Ethical aspects}

All data analysed are publicly available in Brazil, and the procedure to access is described in online supplementary material 2. According to Brazilian legislation (Resolution No. 510 of the National Health Council of Brazil), ${ }^{20}$ studies conducted exclusively with publicly available data are not required to be evaluated by an institutional review board. This study was conducted according to the guidelines and standards for research involving human subjects. $^{21}$

\section{RESULTS}

In 2015, 67777 new patients with TB were reported in Brazil, with an incidence rate of 33.1/100 000 population. The mean annual variation of the triennial moving average of the TB incidence rate in municipalities ranged from $-22.6 \%$ to $41.8 \%$. This interval was wider in small and medium municipalities $(-22.7 \%$ to $41.9 \%)$ rather than in larger ones $(-7.3 \%$ to $14.6 \%)$. A total of 3311 $(59.5 \%)$ municipalities presented a variation between $-8 \%$ and $8 \%$ and were eligible for the analysis for the primary model, including 791 that did not present new patients with TB in 2015.

Regarding socioeconomic variables, household crowding and unemployment rate exhibited the highest associations with $\mathrm{TB}$ incidence rate in both univariate and multiple analysis. The percentages of the poor and vulnerable to poverty population were not included in the multiple model because these factors were strongly correlated with household crowding. On the other hand, the Gini coefficient exhibited a moderate correlation with household crowding (Spearman's $\mathrm{r}=0.55$ ) and a weak correlation with unemployment rate (Spearman's $r=0.31)$. However, the Gini coefficient was not preserved in the multiple model because of inversion of its regression coefficient and an increase in the SE when adjusted. The other socioeconomic variables were not significantly associated with TB incidence rate in the multiple model (table 1).

Based on these two socioeconomic variables, we identified a higher socioeconomic scenario (HSS) cluster, with 3482 municipalities which presented better socioeconomic variables than the 2083 municipalities from the second cluster, the lower socioeconomic scenario (LSS) (table 2). The HSS cluster exhibited unemployment rates of up to $26.9 \%$ and household crowding values between $0.6 \%$ and $28.6 \%$. On the other hand, the LSS cluster exhibited unemployment rates of up to $39.1 \%$; and, household crowding values between $26.6 \%$ and $88.6 \%$ (figure 1).

The mean TB incidence rate in the LSS was 22.1/100 000 population (table 2), which was significantly higher than that observed in the HSS, which was $16.3 / 100000$ population (IRR 1.3; $95 \%$ CI 1.3 to 1.4 ).

Among the 3482 HSS municipalities, 1125 presented at least one notification of patients with TB in 2014 and 2015 and were eligible (annual variation in TB incidence rate between $-8 \%$ and $8 \%$ ) for a secondary modelling. In this analysis, the AIDS case detection rate and the proportion of new patients from at least one vulnerable group were positively associated with the TB incidence rate, while the proportion of contact investigation among new patients with TB presented an inverse association (table 3). 
Table 1 Socioeconomic variables and association with tuberculosis incidence rate in Brazil ( $n=3311$ municipalities + )

\begin{tabular}{|c|c|c|c|c|}
\hline Variable & Mean (SD) & Median (IQ25\%-IQ75\%) & RIIR (95\% CI)§ & $\begin{array}{l}\text { (Adjusted) RIIR } \\
(95 \% \mathrm{Cl}) \S\end{array}$ \\
\hline M-HDI & $0.7(0.1)$ & $0.7(0.6-0.7)$ & $-4.8(-36.9$ to 43.7$)$ & \\
\hline $\begin{array}{l}\text { Average household income } \\
\text { per capita (US\$) }\end{array}$ & $280.3(143.8)$ & $257.9(155.6-372.8)$ & $-0.0(-0.0 \text { to }-0.0)^{\star}$ & \\
\hline GDP per capita (US\$) & $7510.4(8630.3)$ & $5555.2(2909.4-9$ 091.2) & $0.0(-0.0$ to 0.0$)$ & \\
\hline Extremely poor (\%) & $11.4(11.7)$ & $6.5(1.6-19.1)$ & $-0.0(-0.3$ to 0.2$)$ & \\
\hline Poor (\%) & $23.4(18.0)$ & $18.5(6.9-38.8)$ & $0.1(-0.0$ to 0.3$)$ & \\
\hline Vulnerable to poverty (\%) & $44.1(22.7)$ & $42.6(23.3-65.6)$ & $0.2(0.0 \text { to } 0.3)^{\star}$ & \\
\hline Gini coefficient (\%) & $51.0(6.5)$ & $51.0(46.7-55.2)$ & $0.8(0.3 \text { to } 1.2)^{*}$ & \\
\hline Unemployment rate (\%) & $6.7(3.7)$ & $6.3(4.2-8.6)$ & $5.0(4.2 \text { to } 5.8)^{*}$ & $3.9(3.0 \text { to } 4.7)^{*}$ \\
\hline $\begin{array}{l}\text { Illiteracy in the population } \\
\text { with } \geq 18 \text { years }(\%)\end{array}$ & $17.2(10.8)$ & $13.9(8.1-26.4)$ & $-0.4(-0.6 \text { to }-0.1)^{*}$ & \\
\hline $\begin{array}{l}\text { Illiteracy in the population } \\
\text { with } \geq 15 \text { years }(\%)\end{array}$ & $15.6(9.8)$ & $12.9(7.2-23.8)$ & $-0.4(-0.7 \text { to }-0.1)^{\star}$ & \\
\hline Household crowding (\%)ף & $26.4(13.1)$ & $24.7(16.6-33.8)$ & $1.2(1.0 \text { to } 1.4)^{\star}$ & $0.8(0.6 \text { to } 1.1)^{*}$ \\
\hline $\begin{array}{l}\text { Infant mortality rate (no of } \\
\text { deaths in the first year of life } \\
\text { per } 1000 \text { live births) }\end{array}$ & $19.3(7.2)$ & $17.0(13.7-24.1)$ & $0.1(-0.3$ to 0.5$)$ & \\
\hline Life expectancy at birth (years) & $73.1(2.7)$ & $73.4(71.1-75.2)$ & $-0.9(-1.9$ to 0.2$)$ & \\
\hline
\end{tabular}

${ }^{*} \mathrm{P}<0.05$.

†Municipalities with an annual variation in TB incidence rate between $-8 \%$ and $8 \%$ and at least one new TB case in 2015 . $\ddagger$ Variables measured in the last census (2010).

$\S$ The association measure represents the RIIR ((IRR-1)x100), adjusted for the population size of the municipality.

IProportion of the population living in households with more than two people per room.

GDP, gross domestic product; IRR, incidence rate ratio; M-HDI, Municipal Human Development Index; RIIR, relative increment in the incidence rate; TB, tuberculosis.

Regarding the LSS, 1095 municipalities out of 2083 were eligible. The AIDS case detection rate and the proportion of patients from at least one vulnerable group were positively associated with the TB incidence rate. In contrast, the proportion of patients with no record of TB outcome was inversely associated with TB incidence (table 3 ).

Using the variables associated with the outcome in the previous models and considering the TB mortality rate, we defined three clusters for each socioeconomic scenario, making a total of six subscenarios with TB cases in 2014 and 2015. For each socioeconomic scenario, a subscenario (1.0 and 2.0) was also defined including municipalities without TB reporting in 2014 or 2015 (online supplementary material 3).

Figure 2 shows the geographical distribution of municipalities according to the subscenarios. Regarding the subscenarios with patients with TB in HSS, subscenario 1.1 showed the lowest mean rates of TB incidence, AIDS case detection and TB mortality. Subscenario 1.2, despite having relatively low mean rates of TB incidence, AIDS case detection and TB mortality, had a high proportion of patients with no record of TB outcome. Subscenario 1.3 covered $27.8 \%$ of new patients with TB reported in 2015 and presented the highest mean rates of TB incidence, AIDS case detection and proportion of patients from at least one vulnerable group $(22.0 \%)$ (online supplementary material 3$)$.

Regarding the LSS municipalities, subscenario 2.1 had the lowest mean for contact investigation $(36.5 \%)$ and HIV testing $(52.3 \%)$, and the highest mean proportion of patients with no record of TB outcome $(81.8 \%)$. Subscenario 2.2 showed a high TB incidence rate, the highest TB mortality and low HIV testing $(53.5 \%)$ and a high mean proportion of patients with no record of TB outcome $(37.0 \%)$. As a consequence of the inclusion of 14 capitals in subscenario 2.3, it includes $56.3 \%$ of all new patients reported in 2015. Furthermore, subscenario 2.3 has the highest mean AIDS case detection rate in the group of LSS and the second highest TB mortality rate among all subscenarios (online supplementary material 3).

\section{DISCUSSION}

This study classified 5565 Brazilian municipalities in two scenarios (LSS and HSS) defined by socioeconomic variables associated with the TB incidence rate in Brazil. Subsequently, we performed a subclassification based on operational and epidemiological variables associated with the TB incidence rate.

Regarding socioeconomic variables, the unemployment rate was associated with the risk of $\mathrm{TB}$, as found in 
Table 2 Description of socioeconomic scenarios associated with the tuberculosis incidence rate in Brazil $(n=5565$ municipalities)*

\begin{tabular}{|c|c|c|c|c|}
\hline \multirow[b]{2}{*}{ Variables† } & \multicolumn{2}{|c|}{$\begin{array}{l}\text { Higher socioeconomic scenario, } n=3482 \\
\text { municipalities }\end{array}$} & \multicolumn{2}{|c|}{$\begin{array}{l}\text { Lower socioeconomic scenario, } \mathrm{n}=2083 \\
\text { municipalities }\end{array}$} \\
\hline & Mean (SD) & Median (IQ25\%-IQ75\%) & Mean (SD) & Median (IQ25\%-IQ75\%) \\
\hline $\begin{array}{l}\text { TB incidence rate per } \\
100000 \text { population } \neq\end{array}$ & $16.3(31.7)$ & $10.2(0-23.2)$ & $22.1(36.6)$ & $16.9(6.3-29.6)$ \\
\hline $\mathrm{M}-\mathrm{HDI}$ & $0.7(0.1)$ & $0.7(0.6-0.7)$ & $0.6(0.1)$ & $0.6(0.6-0.6)$ \\
\hline $\begin{array}{l}\text { Average household income } \\
\text { per capita (US\$) }\end{array}$ & $330.5(126.5)$ & 324.1 (242.3-403.5) & $181.3(92.4)$ & $150.8(125.3-203.5)$ \\
\hline GDP per capita (US\$) & 8661.1 (7 707.6) & 7259.7 (4758.8-10 053.9) & 4930.5 (8 033.6) & 2937.6 (2371.3-5 004.5) \\
\hline Extremely poor (\%) & $5.8(7.3)$ & $2.6(1.1-7.4)$ & $20.7(11.9)$ & $20.3(12.0-28.7)$ \\
\hline Poor (\%) & $14.2(12.3)$ & $9.7(5.1-20.2)$ & $38.3(15.5)$ & $40.3(29.7-49.1)$ \\
\hline Vulnerable to poverty (\%) & $33.0(17.8)$ & $29.3(19.0-44.9)$ & $62.4(16.5)$ & $67.0(57.0-73.5)$ \\
\hline Gini coefficient (\%) & $58.0(6.0)$ & $48.0(43.9-52.0)$ & $54.1(5.8)$ & $53.8(50.2-57.5)$ \\
\hline Unemployment rate (\%)§ & $5.1(2.9)$ & $4.9(3.1-6.8)$ & $8.3(4.0)$ & $7.6(5.6-10.3)$ \\
\hline $\begin{array}{l}\text { Illiteracy in the population } \\
\text { with } \geq 18 \text { years }(\%)\end{array}$ & $12.9(8.0)$ & $10.7(7.2-16.0)$ & $25.0(10.3)$ & $26.5(17.1-32.9)$ \\
\hline $\begin{array}{l}\text { Illiteracy in the population } \\
\text { with } \geq 15 \text { years }(\%)\end{array}$ & $11.7(7.3)$ & $9.8(6.5-14.6)$ & $22.7(9.5)$ & $23.9(15.6-29.8)$ \\
\hline Household crowding (\%)§』 & $17.1(6.0)$ & $17.3(12.7-22.0)$ & $38.5(10.3)$ & 35.7 (31.2-41.9) \\
\hline $\begin{array}{l}\text { Infant mortality rate (no of } \\
\text { deaths in the first year of life } \\
\text { per } 1000 \text { live births) }\end{array}$ & $16.0(5.0)$ & $14.8(12.8-17.5)$ & $24.6(6.9)$ & $24.2(19.4-29.0)$ \\
\hline $\begin{array}{l}\text { Life expectancy at birth } \\
\text { (years) }\end{array}$ & $74.3(2.1)$ & $74.5(73.2-75.7)$ & $71.1(2.3)$ & $71.1(69.6-72.6)$ \\
\hline
\end{tabular}

*Total of municipalities with socioeconomic data in Brazil that were used in the clusterisation step.

†With the exception of the TB incidence rate (2015), the other variables were measured in the last census (2010).

łlncidence rate ratio $=1.3 ; 95 \% \mathrm{Cl} 1.3$ to 1.4 (lower vs higher socioeconomic scenario).

$\S$ Variables identified in the primary model and used in the first cluster analysis.

IProportion of the population living in households with more than two people per room.

GDP, gross domestic product; M-HDI, Municipal Human Development Index.

previous studies from the USA, ${ }^{22}$ Spain $^{23}$ and Brazil. ${ }^{16}$ At the individual level, unemployment has been associated with an increased risk of alcohol and illicit drug abuse ${ }^{24}$ and with loss to follow-up during HIV treatment. ${ }^{25}$ These factors have already been associated with $\mathrm{TB}$ risk $^{3-5}$ and could at least partially explain the association observed in our study.

Household crowding was also positively associated with the TB incidence rate. In several studies, including some developed in New Zealand, ${ }^{26}$ Lima, ${ }^{27}$ the USA and West

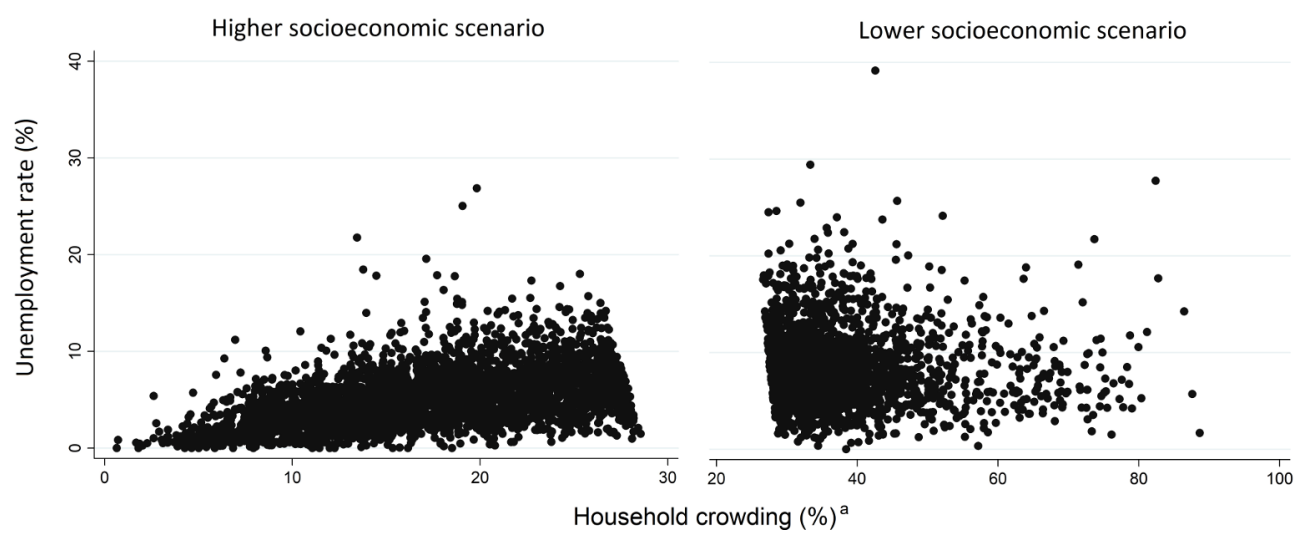

Figure 1 Distribution of Brazilian municipalities according to socioeconomic variables associated with the tuberculosis incidence rate. ${ }^{a}$ Proportion of the population living in holseholds with more than two people per room. 
Table 3 Epidemiological and operational tuberculosis variables associated with the tuberculosis incidence rate stratified by socioeconomic scenarios in Brazil ( $\mathrm{n}=2220$ municipalities)

Higher socioeconomic scenario $n=1125$ Lower socioeconomic scenario $n=1095$ municipalities municipalities $\ddagger$

\begin{tabular}{|c|c|c|c|c|}
\hline Variables† & RIIR (95\% CI)§ & $\begin{array}{l}\text { (Adjusted) } \\
\text { RIIR }(95 \% \mathrm{Cl}) \S\end{array}$ & RIIR $(95 \% \mathrm{Cl}) \S$ & $\begin{array}{l}\text { (Adjusted) } \\
\text { RIIR }(95 \% \mathrm{Cl}) \S\end{array}$ \\
\hline \multicolumn{5}{|l|}{ Epidemiological } \\
\hline $\begin{array}{l}\text { AIDS case detection rate (cases } \\
\text { per } 100000 \text { population) }\end{array}$ & $1.5(1.2 \text { to } 1.7)^{\star}$ & $1.4(1.1 \text { to } 1.6)^{\star}$ & $2.1(1.7 \text { to } 2.5)^{\star}$ & $2.0(1.6 \text { to } 2.4)^{\star}$ \\
\hline $\begin{array}{l}\text { New patients with TB from at } \\
\text { least one vulnerable group (\%)ף }\end{array}$ & $0.5(0.3 \text { to } 0.7)^{*}$ & $0.2(0.1 \text { to } 0.4)^{*}$ & $0.7(0.5 \text { to } 0.9)^{*}$ & $0.5(0.3 \text { to } 0.7)^{*}$ \\
\hline $\begin{array}{l}\text { TB-HIV coinfection among new } \\
\text { patients (\%) }\end{array}$ & $0.3(0.0 \text { to } 0.6)^{\star}$ & & $-0.2(-0.5$ to 0.2$)$ & \\
\hline $\begin{array}{l}\text { New patients with TB who were } \\
\text { prisoners (\%) }\end{array}$ & $0.7(0.4 \text { to } 0.9)^{*}$ & & $1.2(0.9 \text { to } 1.5)^{*}$ & \\
\hline $\begin{array}{l}\text { New patients with TB who were } \\
\text { health professionals (\%) }\end{array}$ & $-0.5(-1.3$ to 0.2$)$ & & $-0.2(-1.0$ to 0.6$)$ & \\
\hline $\begin{array}{l}\text { New patients with TB who were } \\
\text { from an indigenous population } \\
(\%)\end{array}$ & $1.1(0.3 \text { to } 1.9)^{*}$ & & $0.9(0.5 \text { to } 1.2)^{*}$ & \\
\hline $\begin{array}{l}\text { New patients with TB who were } \\
\text { homeless (\%) }\end{array}$ & $0.1(-0.6$ to 0.7$)$ & & $0.1(-0.7$ to 1.0$)$ & \\
\hline $\begin{array}{l}\text { Retreatment patients with TB } \\
\text { among the total patients (\%) }\end{array}$ & $0.5(0.2 \text { to } 0.8)^{*}$ & & $0(-0.3$ to 0.3$)$ & \\
\hline \multicolumn{5}{|c|}{ Operational healthcare (new patients with TB) } \\
\hline Contact examination (\%) & $-0.3(-0.4 \text { to }-0.1)^{*}$ & $-0.2(-0.3 \text { to }-0.1)^{\star}$ & $-0.0(-0.2$ to 0.1$)$ & \\
\hline $\begin{array}{l}\text { Patients with Pulmonary TB with } \\
\text { laboratory confirmation (\%) }\end{array}$ & $0.0(-0.1$ to 0.2$)$ & & $-0.1(-0.3$ to 0.0$)$ & \\
\hline Tested for HIV (\%) & $0.1(-0.0$ to 0.2$)$ & & $0.0(-0.1$ to 0.2$)$ & \\
\hline Cure (\%) & $-0.2(-0.3 \text { to }-0.0)^{\star}$ & & $0.2(0.0 \text { to } 0.3)^{\star}$ & \\
\hline Lost to follow-up (\%) & $0.6(0.3 \text { to } 0.9)^{*}$ & & $0.3(0.0 \text { to } 0.7)^{*}$ & \\
\hline No TB outcome registration (\%) & $0.3(0.1 \text { to } 0.5)^{\star}$ & & $-0.3(-0.5 \text { to }-0.1)^{*}$ & $-0.3(-0.5 \text { to }-0.1)^{\star}$ \\
\hline $\begin{array}{l}\text { Culture examination } \\
\text { (retreatment) }(\%)\end{array}$ & $0.1(-0.1$ to 0.2$)$ & & $0.0(-0.1$ to 0.2$)$ & \\
\hline
\end{tabular}

${ }^{*} \mathrm{P}<0.05$.

tWith the exception of: cure, lost to follow-up, no record of TB outcome and culture examination (2014), the other variables were measured in 2015.

¥Municipalities with an annual variation in TB incidence rate between -8\% and $8 \%$ and at least one new TB case in 2014 and 2015 .

$\S$ The association measure represents the RIIR ((IRR-1)x100), adjusted for the population size of the municipality.

ПHIV, health professional, prisoners, indigenous and homeless.

IRR, incidence rate ratio; RIIR, relative increment in the incidence rate; TB, tuberculosis.

Africa, people living in crowding conditions had a higher risk of TB. ${ }^{28}{ }^{29}$ In Brazil, this variable was already associated with TB incidence and was considered a potential mediator between socioeconomic determinants and TB incidence rate because it may directly favour TB transmission by increasing the contact rate between infected and susceptible people. ${ }^{16}$

In our study, the LSS, with municipalities predominantly in the North, Northeast and Centre-West regions, presented a higher incidence of TB than the HSS, with municipalities located predominantly in the South and Southeast regions. This suggested that classification of municipalities by socioeconomic variables could be highly functional to address TB risk.

Regarding the operational and epidemiological variables, the AIDS case detection rate was positively associated with the TB incidence rate in both socioeconomic scenarios, which was consistent with previous studies in which AIDS has been a factor associated with TB risk at the contextual level. ${ }^{151630}$

The proportion of new patients from at least one vulnerable group was also another factor associated with TB incidence in both scenarios. One of the vulnerable populations included is prisoners. Specifically, in Brazil, 

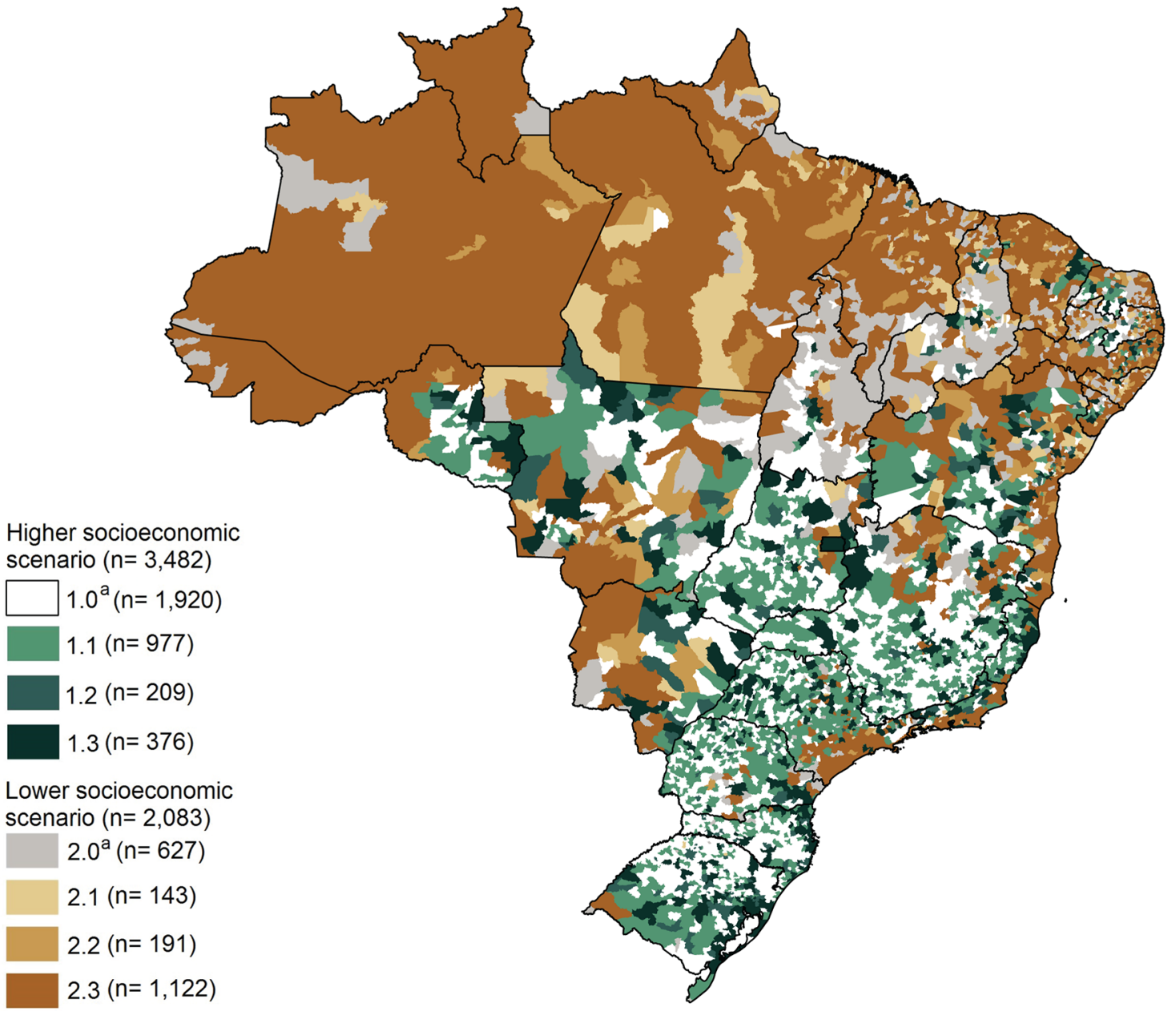

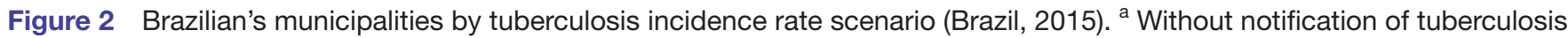
patients in 2014 or 2015.

in 2014, there were approximately 607 thousand imprisoned people in 956 municipalities distributed in all regions of the country, with a prison occupation rate of $161 \% .{ }^{31}$ This overcrowding may explain the higher risk for TB shown by this group in previous studies ${ }^{32}$ and makes it a priority vulnerable group for TB control.

In the HSS, vulnerability was also correlated with the AIDS case detection rate, which is higher in the South and Southeast regions (respectively, 20.1\% and 53.0\% of the AIDS cases identified from 1980 to June 2016). ${ }^{33}$ Regarding the LSS, vulnerability was correlated with indigenous populations, which are predominantly located in the North $(37.4 \%)$, Northeast $(25.5 \%)$ and Central-West regions $(16.0 \%) .{ }^{11}$ These groups have presented a higher risk of TB than other populations. ${ }^{4}$

We observed an inverse association between the TB incidence rate and the percentage of contact investigation in the HSS, which may represent the overall effect on transmission control, possibly through identification and timely treatment. ${ }^{34}$ Finally, in the LSS, the association with the proportion of patients with no record of TB outcome may represent failures in surveillance in collecting these data for the qualification of the information system.
Regarding the absence of patients with TB in 2014 or 2015 in subscenarios 1.0 and 2.0, it is possible that there is under-reporting in these scenarios, mainly in the subscenario 2.0, where there are worse socioeconomic conditions, which are associated with a higher risk of TB. This finding suggests that activities related to TB detection should be strengthened especially in those groups of municipalities.

Concerning the subscenarios that reported at least one patient with TB in the 2years of analysis from the HSS cluster, group 1.1 has the lowest TB incidence rate, better socioeconomic indicators and good TB epidemiological/ operational indicators, suggesting an advanced stage in TB control. Subscenario 1.3 presents the highest TB incidence rate, AIDS case detection rate and proportion of patients from at least one vulnerable group $(22.0 \%)$, especially among prisoners $(12.1 \%)$. In addition, this scenario is composed of mainly by capitals, which could mean a more sensitive surveillance system. Despite subscenario 1.3 corresponding to that with the highest TB risk, the distribution of vulnerabilities suggests a concentrated epidemic in some population groups, including patients with HIV (8.8\% of patients with TB were coinfected) and 
prisoners (12.1\% of new patients), which requires distinct and focused strategies such as screening and prompt treatment.

Subscenarios 1.2 (HSS-cluster), 2.1 and 2.2 (LSS-cluster) need improvement in the information system due to the high proportion of patients with no record of TB outcome. This makes it difficult to analyse the performance of TB control actions. Another challenge in these groups is the investigation of contacts, which was particularly low in subscenario 2.1. Although subscenario 2.1 has the highest percentage of HIV coinfection in new patients with TB $(9.8 \%)$, it also has one of the lowest percentages of HIV testing $(52.3 \%)$, suggesting the underdetection of HIV among people with TB.

In the LSS, group 2.2 exhibited the highest TB incidence, but the lowest proportion of patients from at least one vulnerable group (10.6\%), revealing an endemic situation that is less concentrated in vulnerable populations. Subscenario 2.3 has a reliable information system and good performance in operational activities (eg, contact investigation and HIV testing), revealing that even with limited resources, it is possible to carry out effective disease control actions.

Finally, with the exception of subscenario 2.0, all those in the LSS had a higher TB mortality rate than those in the HSS. Subscenario 2.0, even though no new patients with TB were reported in 2014 or 2015 , exhibited a higher mortality rate than the 1.0 group. Mortality is expected to be less under-reported than incidence, as observed in other diseases. ${ }^{35}$ Thus, the use of this variable for defining clusters contributes to characterising groups according to TB burden besides the other variables used for classification.

\section{Limitations}

As a common limitation of ecological studies, aggregate measures might differ from individual ones. However, these studies provide an overview that contributes to direct decision-making in public policies.

Under-reporting of patients with $\mathrm{TB}$ in Brazil is decreasing each year, ${ }^{1}$ but may remain a potential limitation for this study. Since there is no information about TB case detection and latent TB infection in Brazilian municipalities, the overall burden cannot be estimated. Even so, we hypothesised that the under-reporting is either homogeneous or higher in municipalities with worst socioeconomic indicators. Therefore, the magnitude of association between socioeconomic indicators and TB incidence may be higher than estimated in this study. The exclusion of municipalities that presented high variability in the incidence rate may have reduced the risk of information bias.

On the other hand, although an important number of municipalities was excluded from the regression analysis, those localities were usually small, and the overall municipalities included made up $87.2 \%$ of the Brazilian population. In addition, only five municipalities $(0.1 \%$ of the total) were excluded because of the absence of socioeconomic data. Therefore, we conclude that the association identified in the multiple models can be widely extrapolated.

Concerning data availability, socioeconomic variables by municipality were only available from the last census conducted in the country (2010). Therefore, recent socioeconomic trends and their impact on the current TB incidence rate could not be evaluated. However, we believe that the socioeconomic differences between municipalities have remained proportional in recent years, which allows their evaluation as a determinant of the TB incidence.

\section{Implications for public health and conclusion}

The End TB Strategy proposes bold targets, and a prompt response from each country may be critical for their achievement. We consider this work an innovative tool for public health decisions because we used secondary data available for most of the municipalities of the country with a robust data analysis that recognises the socioeconomic and operational diversity of a continental country. The grouping of municipalities presented in this study has already been incorporated into the National Plan to End $\mathrm{TB}^{12}$ to support the implementation of efficient strategies.

Efforts should be focused on strengthening information systems to provide a reliable picture of the epidemiological situation, such as the implementation of monitoring strategies to ensure the quality of data collection.

There is an inverse relationship between the amount spent with social protection and TB indicators (prevalence, incidence and mortality). ${ }^{37} 38$ The challenges of controlling TB in key populations (prisoners and indigenous) are probably related to their social marginalisation and require integrative collaboration with national social protection programmes run by other divisions of the government.

Municipalities in the LSS, besides additional resources, require actions to reduce the exacerbation of social vulnerabilities, which were reflected in an increased TB risk. In this scenario, TB should be considered a priority in the public health agenda. In addition, municipalities from LSS scenarios that did not have a record of patients with TB in 2015/2014 should focus on activities related to TB detection, especially household-contact investigation as a strategy for active case finding, as this method has been shown to be more effective than standard passive case finding. ${ }^{39} 40$

The heterogeneity of the socioeconomic and epidemiological situation in Brazil, observed in this study, represents a great challenge for $\mathrm{TB}$ control in a country of continental proportions, which may also be the reality in other countries. In this sense, our data analysis approach can be considered by other countries with available variables in order to identify subscenarios to guide targeted actions for TB control. 
Contributors DMP: conceived the study, contributed to the design of the study and the interpretation of results, coordinated and analysed the data including epidemiological models and clusterisation, wrote the first draft of the report, prepared the illustrations, wrote the discussion, critically reviewed the manuscript and approved the final version. MSR and PB: conceived the study, contributed to the design of the study and the interpretation of results, analysed the data including epidemiological models and clusterisation, contributed to the discussion, critically reviewed the manuscript and approved the final version. MNS and ECD: contributed to the design of the study and the interpretation of results, provided significant inputs in the first draft, contributed to the discussion, critically reviewed the manuscript and approved the final version. DA-S, COD, MGJ, KBA, SBC, WNdA, FDC and WMR: contributed to the design of the study and the interpretation of results, contributed to the discussion, critically reviewed the manuscript and approved the final version. ESNA: contributed to the design of the study and results, contributed to the discussion, critically reviewed the manuscript and approved the final version interpretation. FAD-Q: contributed to the design of the study and the interpretation of results, provided significant inputs in the drafts, prepared the illustrations, contributed to the discussion, critically reviewed the manuscript and approved the final version.

Funding The authors have not declared a specific grant for this research from any funding agency in the public, commercial or not-for-profit sectors.

Competing interests None declared.

Patient consent Not required.

Provenance and peer review Not commissioned; externally peer reviewed.

Data sharing statement Contextual data are available from the Brazilian Health Ministry website (www.datasus.gov.br/tabnet/tabnet.htm); Brazilian Institute of Geography and Statistics website (http://www.ibge.gov.br) and the Human Development Atlas in Brazil website (http://atlasbrasil.org.br/2013/). Tuberculosis case data can be made available by Brazilian Health Ministry (http://portalsaude. saude.gov.br). More detailed information about how to access data is described at supplementary material-2.

Open Access This is an Open Access article distributed in accordance with the Creative Commons Attribution Non Commercial (CC BY-NC 4.0) license, which permits others to distribute, remix, adapt, build upon this work non-commercially, and license their derivative works on different terms, provided the original work is properly cited and the use is non-commercial. See: http://creativecommons.org/ licenses/by-nc/4.0/

(c) Article author(s) (or their employer(s) unless otherwise stated in the text of the article) 2018. All rights reserved. No commercial use is permitted unless otherwise expressly granted.

\section{REFERENCES}

1. World Health Organization. Global tuberculosis report 2017. 2017 http://www.who.int/tb/publications/global_report/en/ (accessed 9 Dec 2017).

2. Ministério da Saúde. Indicadores prioritários para o monitoramento do Plano Nacional pelo Fim da Tuberculose como Problema de Saúde Pública no Brasil. Bol. Epidemiológico 2017;48:1-6.

3. San Pedro A, Oliveira RMde. Tuberculose e indicadores socioeconômicos: revisão sistemática da literatura. Revista Panamericana de Salud Pública 2013;33:294-301.

4. Lacerda SNB, Temoteo RCA, de Figueiredo TMRM, et al. Individual and social vulnerabilities upon acquiring tuberculosis: a literature systematic review. Int Arch Med 2014;7:35-8.

5. Millet JP, Moreno A, Fina L, et al. Factors that influence current tuberculosis epidemiology. Eur Spine J 2013;22 (Suppl 4):539-48.

6. Houben RMGJ, Menzies NA, Sumner T, et al. Feasibility of achieving the 2025 WHO global tuberculosis targets in South Africa, China, and India: a combined analysis of 11 mathematical models. Lancet Glob Health 2016;4:e806-e815.

7. Baicker K, Chandra A. Evidence-Based Health Policy. N Engl J Med 2017;377:2413-5.

8. Shin YJ, Ki M, Sung N. A new strategy for tuberculosis control in North Korea. Epidemiol Health 2015;37:e2015053.

9. Sharma DC. New plan to end tuberculosis in south and southeast Asia. Lancet 2017;389:1183.

10. Pai M, Correa N, Mistry N, et al. Reducing global tuberculosis deaths-time for India to step up. Lancet 2017;389:1174-6.

11. Ministério da Saúde. Departamento de Informática do SUS: Informações de saúde (TABNET. Brasília: Ministério da Saúde, 2017. http://www.datasus.gov.br/informacoes-de-saude/tabnet. (accessed 4 Mar 2017).

12. Ministério da Saúde. Plano Nacional pelo Fim da Tuberculose como Problema de Saúde Pública. Brasília: Ministério da Saúde, 2017. http://portalarquivos2.saude.gov.br/images/pdf/2017/junho/29/ plano_nacional_tb_web.pdf. (accessed 9 Dec 2017).

13. Programa das Nações Unidas para o Desenvolvimento - PNUD. Atlas do Desenvolvimento Humano no Brasil: Programa das Nações Unidas para o Desenvolvimento - PNUD, 2015. http://www. atlasbrasil.org.br/2013/pt/consulta/ (accessed 4 Mar 2017)

14. Janssens JP, Rieder HL. An ecological analysis of incidence of tuberculosis and per capita gross domestic product. Eur Respir J 2008;32:1415-6.

15. Dye $\mathrm{C}$, Lönnroth $\mathrm{K}$, Jaramillo $\mathrm{E}$, et al. Trends in tuberculosis incidence and their determinants in 134 countries. Bull World Health Organ 2009;87:683-91.

16. Pelissari DM, Diaz-Quijano FA. Household crowding as a potential mediator of socioeconomic determinants of tuberculosis incidence in Brazil. PLoS One 2017;12:e0176116.

17. Ministério do Desenvolvimento Social e Combate à Fome. Guia de Orientação Técnica - SUAS No 1 Proteção Social Básica de Assistência Social. Brasília: Ministério do Desenvolvimento Social e Combate à Fome, 2005. http://www.pg.pr.gov.br/cmas/wp-content/ uploads/2011/07/guia_orientacao_tecnica.pdf (accessed 4 Mar 2017).

18. Baussano I, Williams BG, Nunn P, et al. Tuberculosis incidence in prisons: a systematic review. PLoS Med 2010;7:e1000381.

19. Kodinariya TM, Makwana PR. Review on determining number of Cluster in K-Means Clustering. International Journal of Advance Research in Computer Science and Management Studies 2013;1:90-5.

20. Conselho Nacional de Saúde. Resolução No 510, de 7 de abril de 2016. Brasília: Conselho Nacional de Saúde, 2016. http://conselho. saude.gov.br/resolucoes/2016/Reso510.pdf (accessed 15 Jan 2017).

21. Conselho Nacional de Saúde. Resolução No 466, de 12 de dezembro de 2012. Brasília: Conselho Nacional de Saúde, 2012. http://bvsms. saude.gov.br/bvs/saudelegis/cns/2013/res0466_12_12_2012.html (accessed 9 Dec 2017).

22. Cantwell MF, McKenna MT, McCray E, et al. Tuberculosis and race/ ethnicity in the United States: impact of socioeconomic status. Am J Respir Crit Care Med 1998;157:1016-20.

23. Díaz de Quijano E, Brugal MT, Pasarín M. ${ }^{a}$ Isabel, et al. Influencia de las desigualdades sociales, la conflictividad social y la pobreza extrema sobre la morbilidad por tuberculosis en la ciudad de Barcelona. Revista Española de Salud Pública 2001;75:517-28.

24. Compton WM, Gfroerer J, Conway KP, et al. Unemployment and substance outcomes in the United States 2002-2010. Drug Alcohol Depend 2014;1:350-3.

25. Támara-Ramírez JR, Álvarez CA, Rodríguez J. Loss of follow-up and associated factors in patients enrolled in the HIV/AIDS program of the Hospital Universitario San Ignacio, Colombia, 2012-2013. Biomedica 2016;36:265-75.

26. Baker M, Das D, Venugopal K, et al. Tuberculosis associated with household crowding in a developed country. J Epidemiol Community Health 2008;62:715-21.

27. Wingfield T, Schumacher SG, Sandhu G, et al. The seasonality of tuberculosis, sunlight, vitamin D, and household crowding. J Infect Dis 2014;210:774-83.

28. Myers WP, Westenhouse JL, Flood J, et al. An ecological study of tuberculosis transmission in California. Am J Public Health 2006;96:685-90.

29. Lienhardt C, Fielding K, Sillah JS, et al. Investigation of the risk factors for tuberculosis: a case-control study in three countries in West Africa. Int J Epidemiol 2005;34:914-23.

30. Kwan CK, Ernst JD. HIV and tuberculosis: a deadly human syndemic Clin Microbiol Rev 2011;24:351-76.

31. Ministério da Justiça. Relatório do Levantamento Nacional de Informações Penitenciárias - Infopen. Brasília: Ministério da Justiça 2014. http://www.justica.gov.br/noticias/mj-divulgara-novo-relatoriodo-infopen-nesta-terca-feira/relatorio-depen-versao-web.pdf. (accessed 21 Mar 2017).

32. Bourdillon PM, Gonçalves CC, Pelissari DM, et al. Increase in Tuberculosis Cases among Prisoners, Brazil, 2009-2014 ${ }^{1}$. Emerg Infect Dis 2017;23:496-9.

33. Ministério da Saúde. Departamento de DST, Aids e Hepatites Virais. Ano V - no 1 - 27a a 53a - semanas epidemiológicas julho a dezembro de 2015 Ano $V$ - no 1 - 01a a 26a - semanas epidemiológicas - janeiro a junho de 2016. Bol. Epidemiológico Aids E DST (2016). Brasília: Ministério da Saúde, 2016. 
34. Pelissari DM, Bartholomay P, Jacobs MG, et al. Offer of primary care services and detection of tuberculosis incidence in Brazil. Revista de Saúde Pública 2018;52:53.

35. Díaz-Quijano FA, Waldman EA. Factors associated with dengue mortality in Latin America and the Caribbean, 1995-2009: an ecological study. Am J Trop Med Hyg 2012;86:328-34.

36. Gibbons CL, Mangen MJ, Plass D, et al. Measuring underreporting and under-ascertainment in infectious disease datasets: a comparison of methods. BMC Public Health 2014;14:147.

37. Reeves A, Basu S, McKee M, et al. Social protection and tuberculosis control in 21 European countries, 1995-2012: a cross-national statistical modelling analysis. Lancet Infect Dis 2014;14:1105-12.

38. Siroka A, Ponce NA, Lönnroth K. Association between spending on social protection and tuberculosis burden: a global analysis. Lancet Infect Dis 2016;16:473-9.

39. Eang MT, Satha P, Yadav RP, et al. Early detection of tuberculosis through community-based active case finding in Cambodia. BMC Public Health 2012;12:469.

40. Fox GJ, Nhung NV, Sy DN, et al. Household-Contact Investigation for Detection of Tuberculosis in Vietnam. $N$ Engl $J$ Med 2018;378:221-9. 